\title{
Innovation and Translation Better way to measure ageing in East Asia that takes life expectancy into account
}

\author{
Sergei Scherbov \\ World Population Program, International Institute for Applied \\ Systems Analysis, Laxenburg, Austria

\section{Warren C Sanderson} \\ World Population Program, International Institute for Applied \\ Systems Analysis, Laxenburg, Austria; Stony Brook University, \\ Stony Brook, New York, USA
}

\section{Stuart Basten}

Department of Social Policy and Intervention, University of Oxford, Oxford, UK

Aim: Population ageing is often held to be one of East Asia's biggest policy challenges. The way population ageing is measured can be improved by taking differences in life expectancy into account.

Method: Using projected life tables, we calculate prospective old age dependency ratios (POADRs) to 2060, placing the boundary to old age at a moving point with a fixed remaining life expectancy ( $R L E)$ for all countries of East Asia.

Results: POADRs grow less rapidly than old age dependency ratios (OADRs). For example, in the Republic of Korea, the OADR is forecast to increase from around 0.1 in 1980 to around 0.8 in 2060, while the POADR is forecast to increase from around 0.1 to 0.4 over the same period.

Conclusion: Policy makers may wish to take into account the fact that the increases in measures of ageing will be slower when those measures are adjusted for changes in life expectancy.

Key words: ageing, demography, East Asia, old age dependency ratio, pension.

\section{Introduction}

'Population ageing' is held as one of the defining features of the policy and scientific literature regarding population challenges over the course of the 21st century in East Asia [1-3]. As well as in countries well known for their aged population and associated challenges such as Japan and Republic of Korea [4], population ageing is also seen as a threat to future economic growth in China, with the oft-quoted expression that the country will 'get old before it gets rich' [5].

Correspondence to: Dr Sergei Scherbov, World Population Program, International Institute for Applied Systems Analysis.

Email:scherbov@iiasa.ac.at
When discussing the implications of an ageing population structure, it is common to think about 'proportions' of populations at different age groups, and their relationships to each other. While some studies use the proportion of the population aged over 65, the vast majority employ the 'old-age dependency ratio', or OADR [6,7]. This is simply the population aged 65 and above divided by the population aged 20 to $64\left(O A D R_{20-64}\right)$.

Currently, over- 65 s account for between 7 and $12 \%$ of the total population of East Asian territories (with the exceptions of Japan $(22 \%)$ and Mongolia $(4 \%))$. In terms of the $O A D R_{20-64}$, these range from 6.5 people aged over 65 per hundred aged 20-64 in Mongolia and 9.9 in Macao SAR, up to 38.9 in Japan with China (12.7), Taiwan (16.1), DPRK (14.6), Republic of Korea (16.9) and Hong Kong SAR (18.7). However, as a result of improving mortality and (often dramatic) declines in fertility, both the proportion aged over 65 and the $O A D R_{20-64}$ for almost every territory in the region are forecast to increase, in some cases substantially. By 2060, the UN forecasts suggest that the proportion aged over 65 will grow to more than $35 \%$ in Japan, Hong Kong SAR, Republic of Korea and Taiwan; around 30\% for Macao SAR and China; just over 20\% for the DPRK; and around 16\% for Mongolia. Furthermore, by 2060, Taiwan, Japan, the Republic of Korea and Hong Kong will have the 3rd, 4th, 5th and 7th highest $O A D R_{20-64}$ in the world, respectively, at around 80 people aged over 65 per 100 aged 20-64 - higher even than any country in Europe, often considered the natural epicentre of population ageing. Using this measurement, China's $O A D R_{20-64}$ is projected to increase from just 12.7 to 53.9 by 2060 - higher than such European countries as the Netherlands, the UK and France. Importantly, in the narrative of regional competition, this is much higher than India (26.1).

Yet it is worth pausing to think more carefully about the measurements we employ - especially if they play such a central role in shaping policy across the region. To take the 'old age dependency ratio', the notion here is that those aged 65 and above are 'dependent' on those aged between 20 and 64. In settings characterised by high rates of informal sector employment and highly differential levels of older-age and female labour force participation, this notion of dependency is highly problematic.

Crucially, however, it is important to reconsider what we mean by 'old' and/or 'dependent'. As observed elsewhere [8], the roots of the OADR lie in the Bismarckian/early 20th 
century idea of old age and dependency being fundamentally linked to pension entitlement which, in turn, was linked to the onset of decrepitude. Yet in terms of life expectancy, and as a wide array of literature suggests in terms of more general health [9-11], judging ageing in the 21st century on these terms appears to be anachronistic. Though both old and emerging public health issues clearly exist, tremendous improvements in access to health care have been seen across East Asia which have dramatically contributed to lowering mortality [12].

Sanderson and Scherbov have defined a number of new methods to 'remeasure age', taking into account changes in life expectancy. They define the threshold of old age based upon a fixed remaining life expectancy $(R L E)$, not a fixed number of years already lived. Various studies have sought to identify a suitable RLE (see [13] for a review). A general consensus has emerged to consider an RLE of 10 to 15 years. Sanderson and Scherbov [14] suggest basing this boundary upon an $R L E$ of 15 years [hereafter $R L E_{15}$ ] because this was the remaining life expectancy of 65 -year-olds in many low mortality countries in the 1960 s.

So far, we have tried to justify moving away from the chronological age of 65 as a boundary to 'old age' and 'to think prospectively', taking the year at which $R L E_{15}$ occurs to be a more useful boundary. Our objective here, therefore, is to elucidate an alternative way of measuring population ageing which takes the current demographic situation into account and apply this to East Asia.

\section{Methods}

With the above in mind, we proceed to calculate the POADR based upon $R L E_{15}$ for the countries of the East Asia UN Region per the formulae below. For this exercise, we utilise the input data from the UN's World Population Prospects: 2012 Revision including the UN life tables $\left(l_{x}\right)$ which are graduated to single years of age and time.

$$
\begin{gathered}
O A D R_{20-64}=\frac{\text { Number of people } 65 \text { years or older }}{\text { Number of people aged } 20 \text { to } 64} \\
\text { Number of people older }
\end{gathered}
$$

We provide an example of the calculation of the POADR using UN data for Japan in 2020. According to the UN, the age at which remaining life expectancy would equal 15 in the life table for both genders combined would be 73.9. The numerator of the POADR is the number or proportion of the population who is 73.9 years old or older. The proportion of the Japanese who are forecasted to be 73.9 years old or older in 2020 is 0.164 . The denominator of the POADR is the number or proportion of the population between age 20 and age 73.9. In Japan in 2020, this is forecasted to be 0.665 . The $P O A D R$ in Japan in 2020 , then, is 0.164 divided by 0.665 , which equals 0.246 .

\section{Results}

Figure 1 compares the POADR and the $O A D R_{20-64}$ for the countries of East Asia. A number of patterns emerge. For one group of countries characterised by low fertility - or continuing transition to low fertility - and improving mortality, the gap between the POADR and the $O A D R_{20-64}$ is large. For these places - namely Taiwan, Republic of Korea, Macao SAR, Hong Kong SAR and Japan - population ageing will continue to be a feature of their 21 st century demographic landscape, but switching to a prospective measurement suggests that the increases in 'dependency' when judged differently may be much less dramatic. For a second group of countries which are characterised by rather higher rates of fertility and lower levels of mortality improvement (namely Mongolia and DPRK), the difference between the two ratios is more marginal. China is an important 'middle-ground' country between these groups. While measuring 'dependency' prospectively does not have the same dramatic impact as in other low-fertility regimes, by 2060 it still means a decrease from an $O A D R_{20-64}$ of almost 0.6 down to a POADR of around 0.3.

\section{Conclusions}

Based on conventional measures such as the $O A D R_{20-64}$, East Asia is increasingly seen as a global epicentre for rapid population ageing. Yet it is important to distinguish a number of important features when applying what is, essentially, a European measure of ageing to this region. Certainly there are structural systems in place in many East Asian settings which provide support for older people. However, simply applying the 'European' notion of 65 as a boundary to dependency is inadequate not only both on the grounds of improving health and life expectancy (as described above) but also from a policy perspective. China, of course, has a patchwork of different pension systems, each with different conditions and payment levels [16]. As Park and Estrada [17] note, many Asian public pension systems are characterised by 'systematic weaknesses' including low coverage and inadequate benefits and, as such, 'still have a long way to go in terms of affordable, adequate and sustainable old age economic security'. In addition, 65 is only a boundary to pension provision in a minority of countries, again questioning the age as a 'special' marker. Finally, in settings characterised by provident fund-based systems, the relationship between 'workers' and 'pensioners' is arguably much less important [18].

A related policy issue is that the structural care system, which the European 'old age' vision is based upon, is frequently lacking in many parts of East Asia where 'filial obligation' and the role of the family are prioritised over state provision [19]. This is not to say, however, that increased state support is not wanted - far from it according to one recent study from 


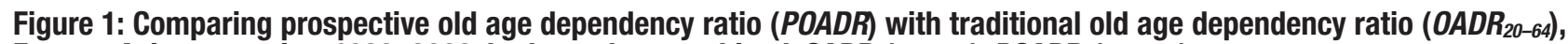
Eastern Asian countries, 1980-2060, both genders combined. OADR (- $(-)$; POADR ( - - - .).

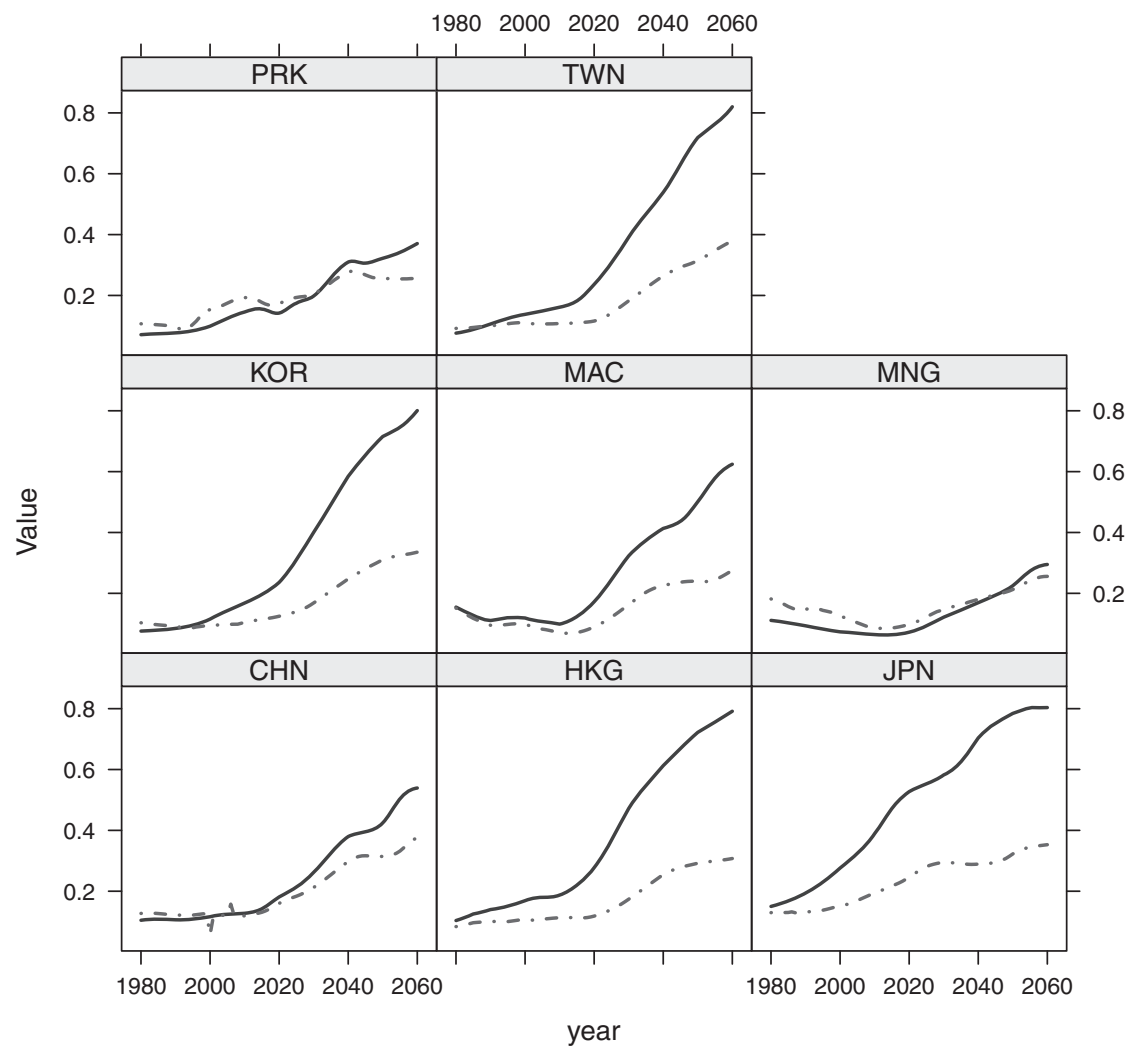

Source: Authors' calculations based on [15]. Data file for this figure can be downloaded from www.reaging.org/indicators.

China [20]. However, measuring the burden of a large-scale state support system which simply is not there in many cases and, again, is based upon an assumption that this system would be strained solely by an increase in the proportion of the population aged over 65 , seems to be a fruitless exercise. Yet even in those settings such as the Republic of Korea and Japan where (relatively) comprehensive old-age benefits exist, the boundary to accessing such benefits is not 65 [17].

East Asia is often frequently presented as a new global epicentre of population ageing. Yet upon closer inspection, it is invariably found that both scholarly and grey literature rely upon measures of population ageing - such as the OADR which, we argue, are not fit for purpose. Here we have presented an alternative measurement which, by taking into account improvements in life expectancy, represents a first step away from the reliance upon the $O A D R$ and, as such, perhaps towards a more realistic view of population ageing in East Asia.

\section{Acknowledgement}

This work was supported by the European Research Council under Grant Agreement Number ERC2013-AdG 323947Re-Ageing.

\section{Key Points}

- In the coming decades, the countries of East Asia are expected to exhibit a rapid increase in conventional measures of ageing like old age dependency ratio (OADR) or median age.

- Considering age 65 as a threshold of being old and a boundary to dependency is inadequate not only both on the grounds of improving health and life expectancy but also from a policy perspective.

- Using new measures of ageing, when the threshold age of who is considered old depends on life expectancy, may considerably change the picture of ageing and make it much less dramatic especially for several East Asian places like Taiwan, Republic of Korea, Macao SAR, Hong Kong SAR and Japan.

\section{References}

1 Cheng S-T, Lum T, Lam LCW, Fung HH. Hong Kong: Embracing a fast aging society with limited welfare. The Gerontologist 2013; 53: 527533.

2 Eggleston K, Tuljapurkar S. Aging Asia: The Economic and Social Implications of Rapid Demographic Change in China, Japan, and South Korea. Stanford, CA: APARC Books, 2010. 
3 National Research Council. Aging in Asia: Findings from New and Emerging Data Initiatives. Washington, DC: National Research Council, 2012. [Cited ••.] Available from URL: http://www.nap.edu/catalog/13361/ aging-in-asia-findings-from-new-and-emerging-data-initiatives

4 Clark RL, Ogawa N, Kondo M, Matsukura R. Population decline, labor force stability, and the future of the Japanese economy. European Journal of Population = Revue Européenne de Démographie 2009; 26: 207-227.

5 Cai F. 'Ageing before affluence' and China's sustainable economic growth. International Economic Review 2012; ••: 82-95.

6 Horioka CY. Ageing and saving in Asia. Pacific Economic Review 2010; $\bullet \bullet:$ 46-55.

7 Holzmann R, Mac Arthur IW, Sin Y. Pension Systems in East Asia and the Pacific: Challenges and Opportunities, Social Protection Discussion Paper Series 0014. Washington, DC: The World Bank, 2000. [Cited ••.] Available from URL: http://documents.worldbank.org/curated/en/2000/06/ 1615004/pension-systems-east-asia-pacific-challenges-opportunities

8 Basten S. Redefining 'old age' and 'dependency' in East Asia: Is 'prospective aging' a more helpful concept? Asian Social Work and Policy Review 2013; 7: 242-248.

9 Nybo $\mathrm{H}$ et al. Functional status and self-rated health in 2,262 nonagenarians: The Danish 1905 Cohort Survey. Journal of the American Geriatrics Society 2001; 49: 601-609.

10 Vaupel JW. Biodemography of human ageing. Nature 2010; 464: 536542.

11 Christensen K, Doblhammer G, Rau R, Vaupel JW. Ageing populations: The challenges ahead. Lancet 2009; 374: 1196-1208

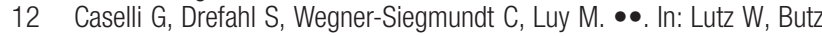
WP, KC S, eds. World Population and Human Capital in the 21st Century.
Oxford: Oxford University Press, 2014: 226-272. [Cited ••.] Available from URL: http://ukcatalogue.oup.com/product/9780198703167.do

13 Basten S, Yip P, Chui E. Remeasuring ageing in Hong Kong SAR; or 'keeping the demographic window open'. Journal of Population Research 2013; 30: 249-264.

14 Sanderson WC, Scherbov S. Remeasuring aging. Science 2010; 329: 1287-1288.

15 United Nations. World Population Prospects: The 2012 Revision. New York, NY: Department of Economic and Social Affairs, Population Division, 2013. [Cited ••.] Available from URL: http://esa.un.org/wpp/Excel-Data/ EXCEL FILES/3 Mortality/ WPP2012_MORT_F13_3_LIFE_EXPECTANCY_60_FEMALE.XLS

16 Dorfman MC et al. China's Pension System: A Vision, Directions in Development - Human Development. New York, NY. The World Bank, 2013 [Cited ••.] Available from URL: http://elibrary.worldbank.org/doi/book/ 10.1596/978-0-8213-9540-0

17 Park D, Estrada GB. Emerging Asia's Public Pension Systems: Challenges and Reform Efforts. Designing Fiscally Sustainable and Equitable Pension Systems in Asia in the Postcrisis World. Tokyo, Japan: IMF, 2013.

18 Chan CK. Protecting the ageing poor or strengthening the market economy: The case of the Hong Kong Mandatory Provident Fund. International Journal of Social Welfare 2003; 12: 123-131.

19 Mason KO. Family change and support of the elderly in Asia: What do we know? Asia-Pacific Population Journal 1992; 7: 13-32.

20 Chen L, Yang DL. Old age care concerns and state-society relations in China: Public anxiety and state paternalism. Journal of Asian Public Policy 2012; 5: 136-154. 